\title{
A NEW COLOUR VISION TEST FOR CLINICAL USE
}

\author{
CHEE HING KON and DILOGEN DE ALWIS \\ Guildford
}

\begin{abstract}
SUMMARY
Several tests are available for assessing colour vision but they can be expensive, complicated or too time consuming to perform. We have produced a new plate test based on pseudoisochromatic principles. The test, using an error score, examines both the red-green and blue-yellow axes, with four levels of difficulty for each axis. Results from a pilot study show that error scores from congenital red-green blind subjects are significantly higher than those of age-matched controls $(p<0.01)$ only when using the red-green plates and not the blue-yellow plates. In optic neuritis patients, error scores using both the red-green and blue-yellow plates were significantly higher than those of controls throughout the 6 month follow-up. The test, including scoring, takes 6 minutes to complete. These preliminary results suggest that the new test is effective for screening congenital red-green blindness and monitoring colour vision defects in acquired diseases such as optic neuritis.
\end{abstract}

Assessment of colour vision is important in the diagnosis and management of many ophthalmic and neurological diseases. ${ }^{1-4}$ In a busy clinic, a colour vision test is only practical if it is simple to use and quick to perform. ${ }^{5,6}$ It also has to be relatively inexpensive. The Ishihara test ${ }^{7}$ satisfies the above criteria and for this reason is perhaps the most widely used colour vision test in the clinic. It does, however, have major limitations.

The Ishihara test was originally designed to identify congenital red-green defects, for which it is very effective. ${ }^{8-10}$ It does not test the blue-yellow (tritan) axis, which although not affected in congenital red-green blindness can be defective in acquired diseases such as optic neuritis, ${ }^{11,12}$ retinitis pigmentosa, ${ }^{2,13}$ and chorioretinitis. ${ }^{2}$ In some acquired defects such as diabetic retinopathy, which affects mainly the blue-yellow axis, ${ }^{14-16}$ the Ishihara

From: Department of Ophthalmology, Royal Surrey County Hospital, Guildford, Surrey,UK.

Correspondence to: Mr C. H. Kon, 44A Courtfield Gardens, London SW5 0LZ, UK. test will be of limited use. ${ }^{1.8}$ It is estimated that $8 \%$ of the male population has congenital red-green blindness ${ }^{17,18}$ and would fail the Ishihara test. When such a patient develops an acquired colour vision defect, the Ishihara test cannot then be used to examine the new defect. Moreover, the clinician may be misled if unaware of the existence of a congenital defect. A more useful test would be one that examines both the red-green and blue-yellow axes.

The Ishihara test was designed largely as a qualitative test - patients either do very well or very badly. The test is not sufficiently sensitive to identify those with mild red-green colour defects, who tend to pass undetected. It is known that in acquired conditions the degree of colour vision defect varies with disease status, and in these conditions where monitoring of fluctuations is required, the Ishihara test is unhelpful.

The Farnsworth-Munsell 100-hue test ${ }^{19,20}$ is a quantitative test which was also originally designed to detect congenital colour blindness but is now used for acquired diseases as well. The test relies on the subject's colour matching ability, which is independent of their colour vision status. ${ }^{6}$ The test is inefficient at estimating the degree of colour vision loss along a particular confusion axis, as the data for each axis rely on only a small proportion of the total number of caps. Once the results are obtained, unless the subject has a dense defect along a particular colour axis, interpretation can often be difficult. Because it is time consuming to perform and score up to 20 minutes for each eye $e^{21}$ - the test is impractical for routine use in the clinic. ${ }^{22}$

We have designed a new set of pseudoisochromatic plates which attempts to redress the limitations discussed. This new test examines two axes: the redgreen and blue-yellow axes. It can therefore identify congenital red-green defects and, in their presence, be used to detect any abnormalities in colour vision resulting from acquired diseases such as optic neuritis. It can also be used for acquired diseases which affect mainly the blue-yellow axis. Furthermore the plates are graded, so that the degree of 
defect can be recorded and used to monitor fluctuations in the disease status.

\section{DESIGN OF THE PLATES}

The test comprises 17 plates. The first plate (plate 0 ) is a control plate; plates $1-8$ are designed to test the red-green confusion axis; plates 9-16 test the blueyellow confusion axis.

Plates 0, 1 and 9 from the test are shown in Figs. 1, 2 and 3 respectively. Each plate consists of six groups of randomly distributed grey spots of varying shades. In one of the six groups, some of the grey spots are replaced by a different colour which lies on either the red-green or blue-yellow confusion axes. It is this odd-one-out group with the replacement colour that the subject has to identify. A red-green colour blind subject cannot differentiate between grey and the replacement colour ${ }^{6}$ that lies on the red-green axis and will not be able to identify this odd-one-out group. Similarly, subjects with blue-yellow defects will be unable to identify replacement colours on the blue-yellow axis. Visual clues due to luminosity differences have been eliminated by using varying shades of grey with photopic reflectance above and below that of the coloured spots.

Validation of the chosen hue, saturation and luminosity of the coloured spots was carried out using a telespectroradiometer. This captures the spectral power distribution of light reflected from one spot relative to that reflected from a standard white surface (Halon). A tungsten halogen source was directed towards the surface of the plate at an angle of incidence of 45 degrees. Light reflected normal to the surface was imaged on an optic fibre that directed the captured light to a monochromator. This viewing sytsem represents the normal viewing conditions. ${ }^{6}$ The reflectance relative to the standard white surface was worked out and the Commission Internationale de l'Eclairage (CIE) $1976 \mathbf{u}^{\prime} \mathrm{v}^{\prime}$ coordinates $^{23}$ for the spots were calculated. The chromaticity coordinates for the red-green and blueyellow plates are shown in Tables I and II and plotted on the CIE 1976 Uniform Chromaticity Scale Diagram (UCS) as shown in Fig. 4. The 1976 CIE UCS diagram is a plot of the $\mathrm{v}^{\prime}$ against $\mathrm{u}^{\prime}$ values of the colours. The loci of colours likely to be confused by protanopic observers emanate from the point $P$ $\left(\mathrm{u}^{\prime}=1.020, \mathrm{v}^{\prime}=0.477\right)$; by deuteranopic observers from point $D\left(\mathrm{u}^{\prime}=-0.534, \mathrm{v}^{\prime}=0.680\right)$; and by tritanopic observers from point $T\left(\mathrm{u}^{\prime}=0.251, \mathrm{v}^{\prime}=\right.$ $0.0)$. The point of equal energy with equal illuminant has the $u^{\prime}$ value of 0.21051 and $v^{\prime}$ value of 0.47366 . From the diagram it can be seen that the red-green and blue-yellow spots in the new test will be confused by red-green and blue-yellow vision defective subjects respectively. ${ }^{23}$ However, the shortcoming of using these specific chromaticities is that it assumes that colour vision defects lie along the two confusion axes, and it therefore omits to test the discrimination of other hues. The test therefore has limitations in testing some acquired dyschromatopsias which may have defects along other confusion axes. Menage and co-workers ${ }^{24}$ have shown that optic neuritis can present with non-specific colour vision loss which does not lie along any particular axis.

Four levels of difficulty have been designed by altering the degree of saturation of the replacement colour. Low-saturation replacement spots more closely resemble the grey spots than do highsaturation replacement spots. Low-saturation spots will therefore be more difficult to identify. It follows that spots of low saturation will be discernible only by subjects with milder defects. Subjects with dense defects will be able to identify only spots of higher saturation. A simple scoring system based on the inability to identify the odd-one-out plate, i.e. error score, has been devised to enable rapid and easy interpretation of the results.

\section{PERFORMING AND SCORING THE TEST IN THE CLINIC}

The test should be performed under CIE Illuminant ' $C$ ' illumination using the Macbeth Easel lamp ADE 10 or equivalent at a distance of two-thirds of a metre. Refractive errors should be corrected and each eye tested in turn.

The 17 plates are labelled consecutively as plate 0 to plate 16. The subject is told that one of the six groups of spots on each plate contains a colour other than grey and it is this group that has to be identified. The subject is given approximately 10 seconds per plate.

The first plate (plate 0) is a control plate and a correct answer should be obtained from all subjects irrespective of their colour vision status. If a wrong answer is given, this may be due either to a very poor visual acuity or malingering and the test should be abandoned. As every subject should be able to identify the odd-one-out group on this plate, it can also be used to convey the simple instructions to those subjects who have difficulty in understanding, e.g. young children or those with language difficulties.

Plates 1 to 8 test the red-green confusion axis. The level of difficulty increases every two consecutive plates. Therefore plates 1 and 2 are the easiest and plates 7 and 8 the most difficult. Plates 9 to 16 test the blue-yellow axis and are arranged in a similar way to the red-green plates.

A score sheet is available for use in conjunction with the test (Fig. 5). On the score sheet, each block represents a plate and the correct location of the odd-one-out group is indicated by ' $x$ '. The number at 

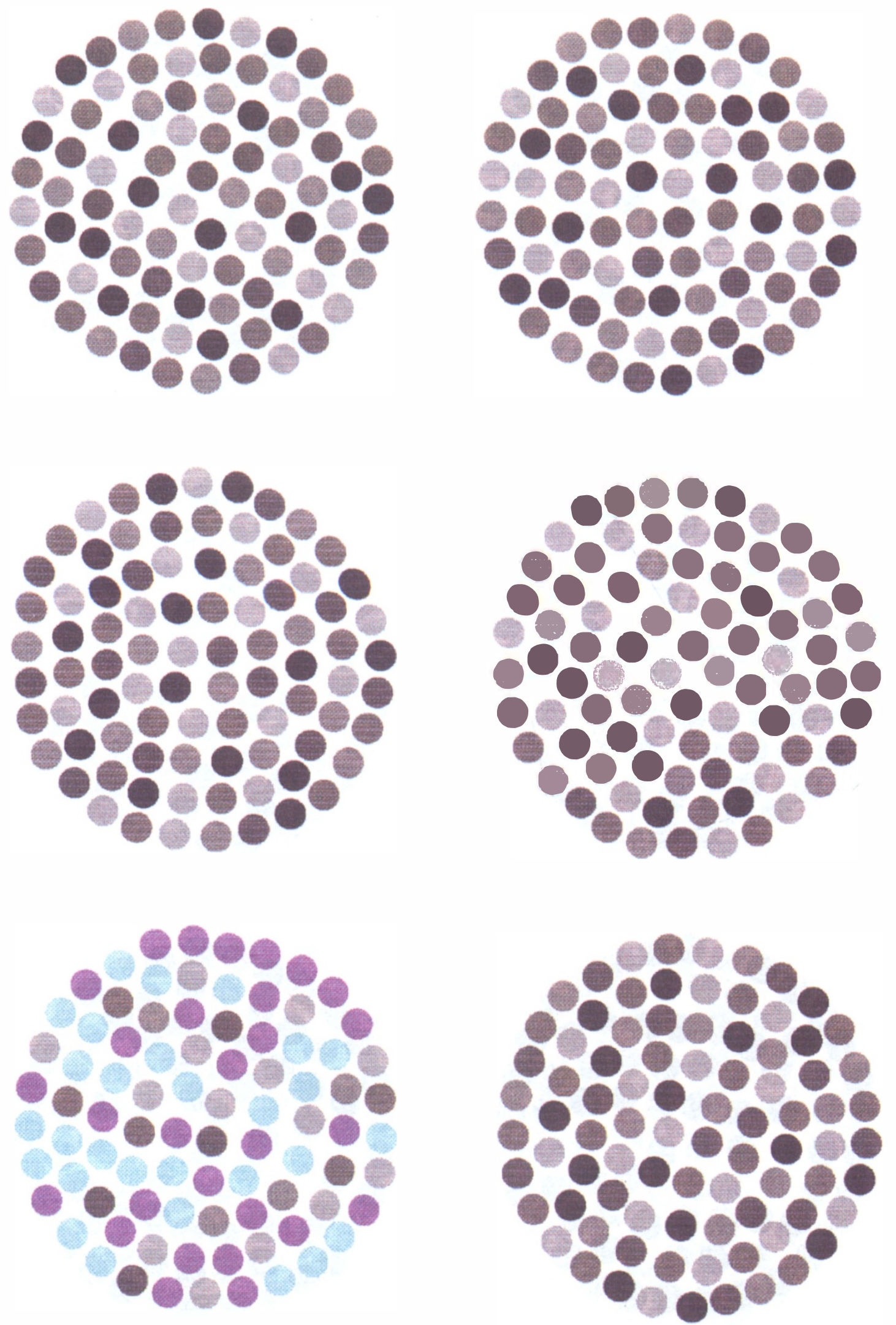

Fig. 1. Plate 0. (Plates reproduced here are for illustration only and should not be used to test patients. This is due to the lack of colour control in the printing.) 

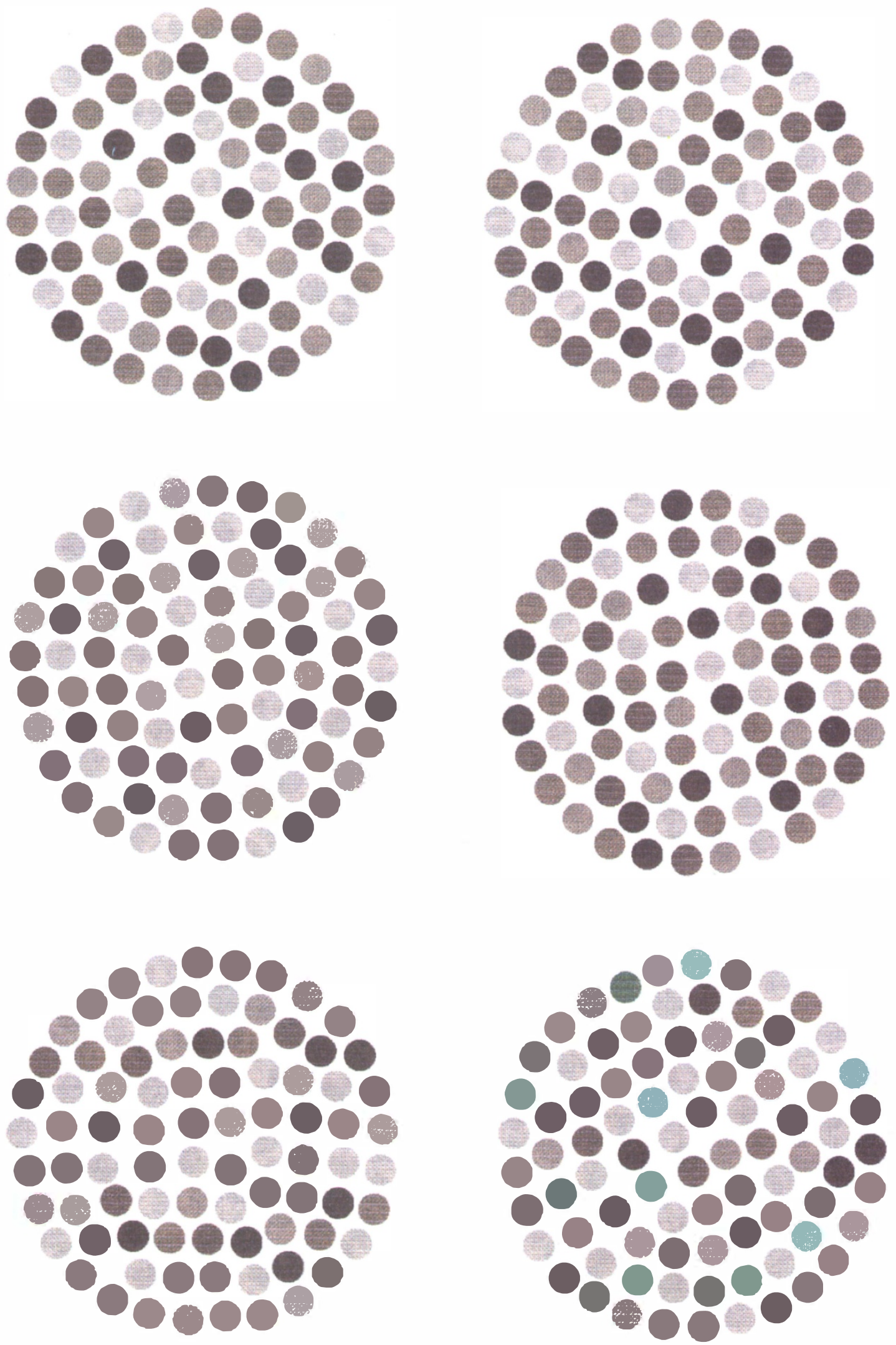

Fig. 2. Plate 1. (Plates reproduced here are for illustration only and should not be used to test patients. This is due to the lack of colour control in the printing.) 

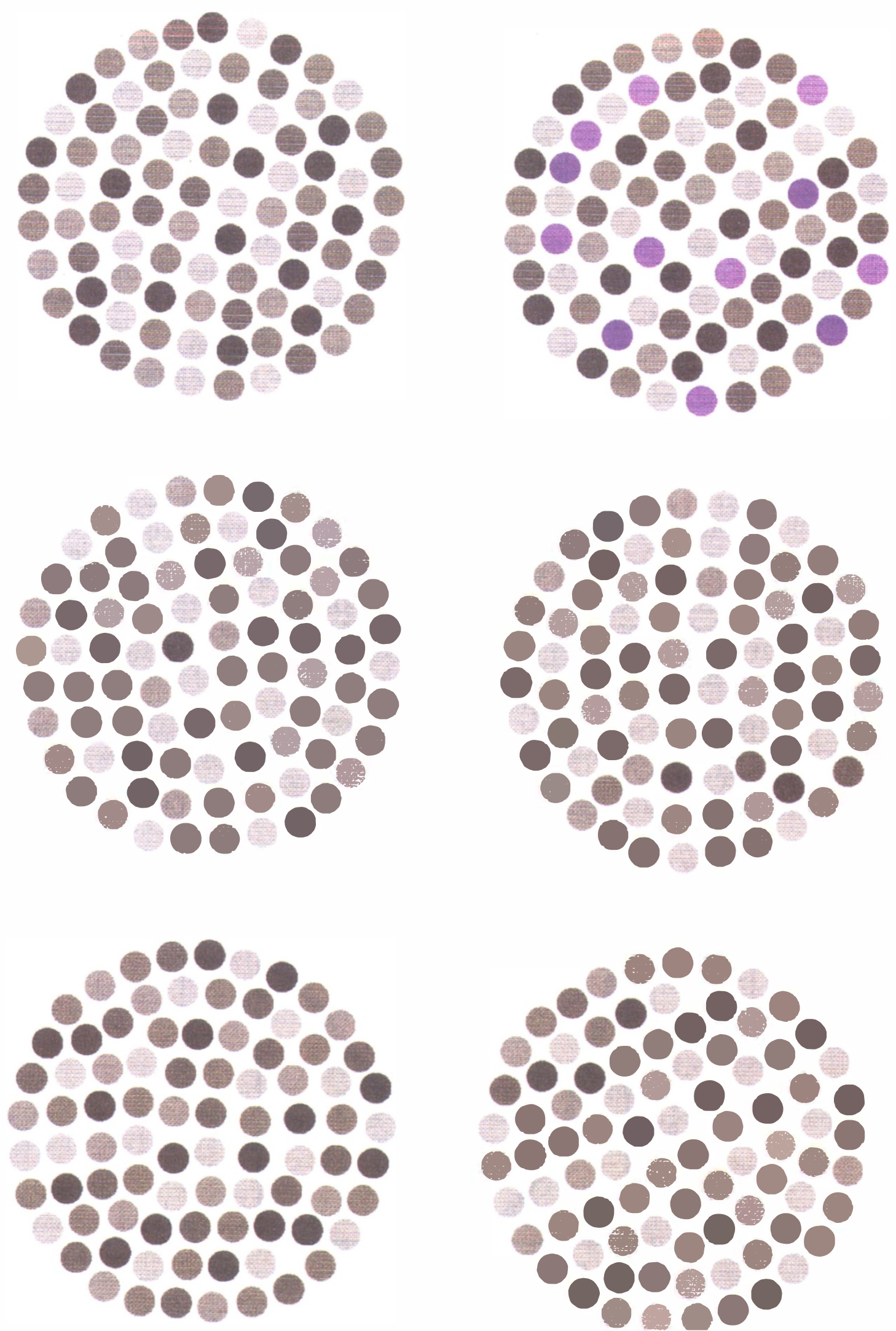

Fig. 3. Plate 9. (Plates reproduced here are for illustration only and should not be used to test patients. This is due to the lack of colour control in the printing.) 
Table I. Chromaticity coordinates for the red-green plates

\begin{tabular}{|c|c|c|}
\hline \multirow[b]{2}{*}{ Red-green plates } & \multicolumn{2}{|c|}{ Chromaticity coordinates } \\
\hline & $\mathrm{u}^{\prime}$ coordinate & $\mathrm{v}^{\prime}$ coordinate \\
\hline Plates 1 and 2 & 0.1360 & 0.4890 \\
\hline Plates 3 and 4 & 0.1572 & 0.4880 \\
\hline Plates 5 and 6 & 0.1856 & 0.4830 \\
\hline Plates 7 and 8 & 0.2006 & 0.4760 \\
\hline
\end{tabular}

the top left-hand side of each block is the plate number. The number on the right-hand side is the error score. No score is given for a correct answer, i.e. if the subject correctly identifies the group with the replacement colour. If a wrong answer is given, the examiner circles the 'error score' on the right of each block. At the end of the test the total score for the red-green and blue-yellow defects for each eye is calculated by adding up the circled error scores. The higher the score, the denser the defect. A total of 0 is a perfect score and a score of 20 indicates that the patient has failed all the plates in the series.

\section{PATIENTS AND METHOD}

Fourteen patients with congenital red-green blindness (4 protanopic and 10 deuteranopic) as diagnosed by plates 2 to 21 of the Ishihara test and 14 age-matched controls with no past history of ocular disease were selected. All patients and controls had a visual acuity of $6 / 9$ or better in at least one eye. There were no demographic differences between patient and controls in sex and age (patients 20-56 years, mean 37.2 years; controls $20-57$ years, mean
Table II. Chromaticity coordinates for the blue-yellow plates

\begin{tabular}{lcc}
\hline & \multicolumn{2}{c}{ Chromaticity coordinates } \\
\cline { 2 - 3 } Blue-yellow plates & $\mathrm{u}^{\prime}$ coordinate & $\mathrm{v}^{\prime}$ coordinate \\
\hline Plates 9 and 10 & 0.2153 & 0.3930 \\
Plates 11 and 12 & 0.2089 & 0.4220 \\
Plates 13 and 14 & 0.2086 & 0.4480 \\
Plates 15 and 16 & 0.2053 & 0.4690 \\
\hline
\end{tabular}

37.4 years). The new test was administered under the same lighting condition as the Ishihara test and scores were obtained.The patients were then examined by an ophthalmologist to exclude any ocular pathology. As congenital red-green colour blindness is bilateral and usually equal in both eyes, ${ }^{8}$ scores from the right eye were used in the analysis unless the visual acuity was less than $6 / 9$, in which case the score from the left eye was used. The same scoring method was used for controls.

Optic neuritis was the acquired condition chosen for this study. Eleven patients presenting with the first episode of demyelinating optic neuritis and satisfying the criteria set out by Menage et al. ${ }^{24}$ (Table III) were selected. Patients had an age range of 24-44 years, mean 33.5 years. Eleven age-matched controls (age range 24-46 years, mean 34.1 years) with visual acuities of $6 / 9$ or better and no past history of ocular disease were chosen. Controls were tested on only one occasion to obtain their visual acuity and scores using the new test. The patients were examined at presentation and at 1 month, 3 months and 6 months. At each visit, the Snellen

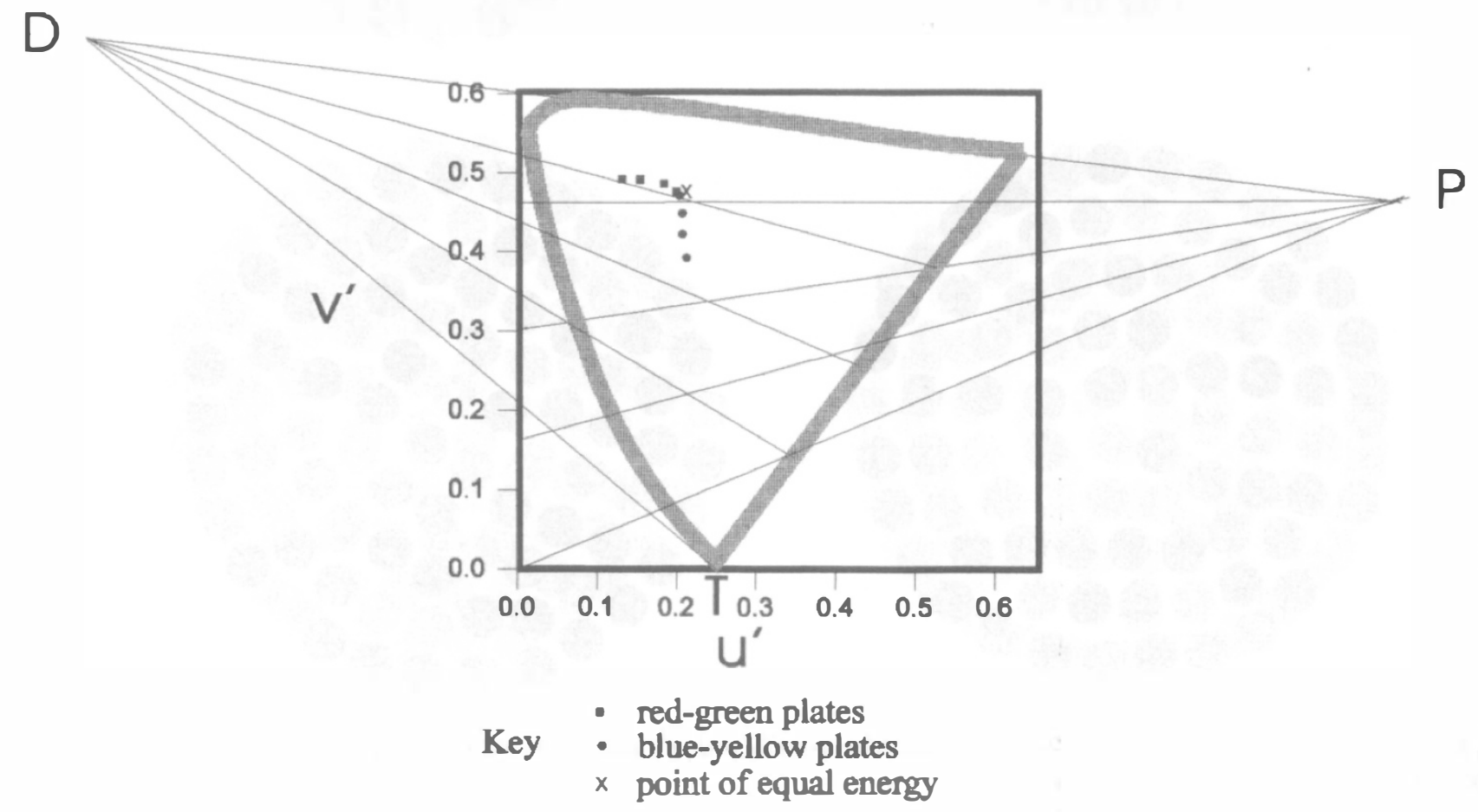

Fig. 4. CIE 1976 Uniform Chromaticity Scale Diagram showing protanopic $(P)$, deuteranopic $(D)$ and tritanopic $(T)$ confusion lines in relation to the chromaticities of the stimuli used in the new test. 
Name :

No :

Date:

DOB /Age :

Diagnosis :

VA $\mathbf{R}=$

$\mathbf{L}=$
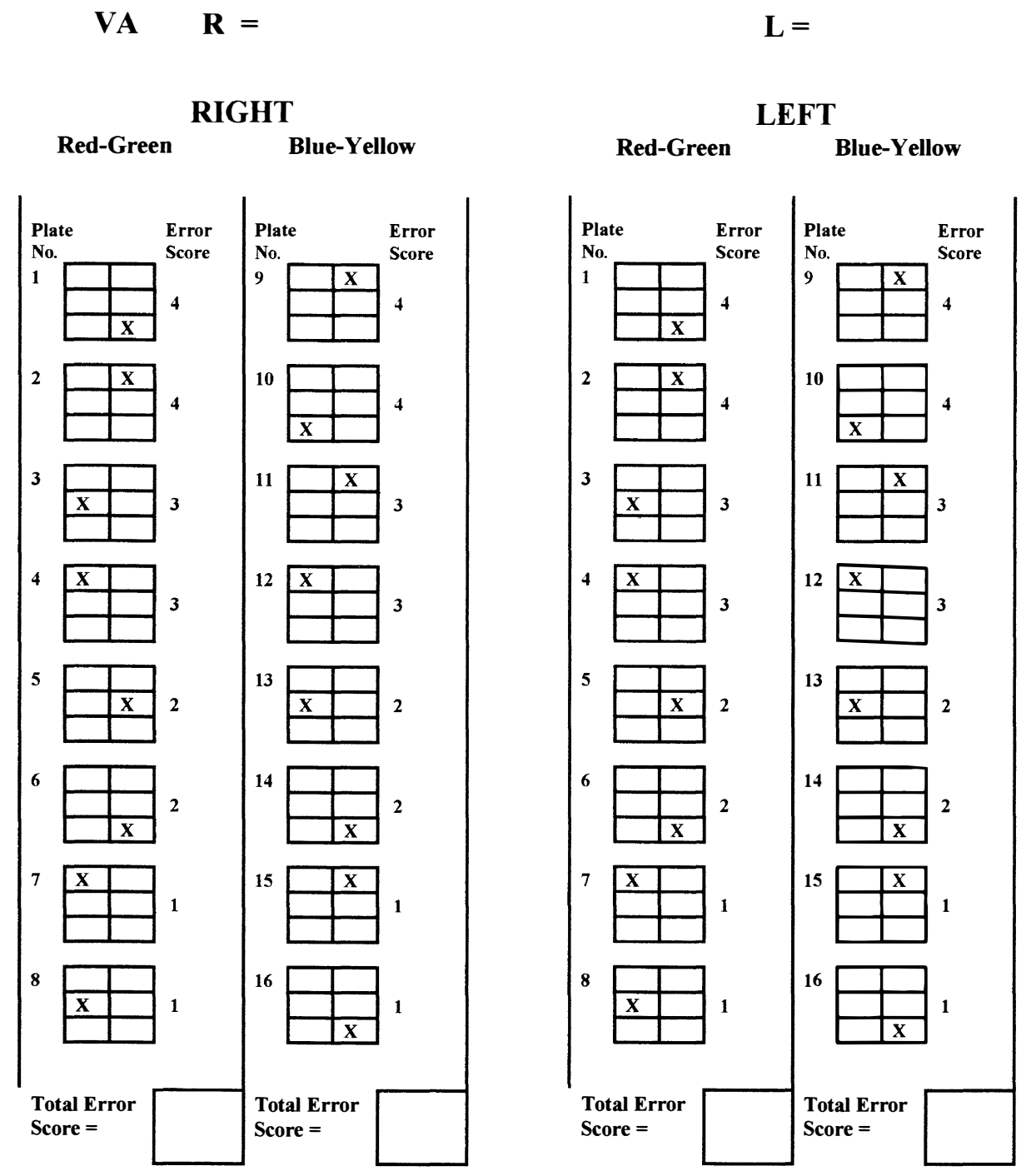

Fig. 5. Score sheet.

visual acuity and the new colour vision test were repeated. Patients were also examined by an ophthalmologist to exclude any other ocular pathol-

Table III. Criteria for optic neuritis patients ${ }^{24}$

1. Age $18-50$ years

2. No previous episode of optic neuritis or diagnosis of optic neuritis

3. No history of congenital colour vision abnormality

4. Normal vision in both eyes before the acute optic neuritis

5. Reduced acuity in the affected eye at presentation to the casualty department

6. Relative afferent pupillary defect in the affected eye at presentation

7. Significant delay in the visual evoked potential in the affected eye

8. First examination within 31 days of the onset of any symptoms ogy. All patients had a visual evoked potential test during the 6 month follow-up period to confirm optic nerve dysfunction.

\section{RESULTS}

The new test scores colour vision defects from 0 (no deficit) to 20 (dense deficit). Statistical analysis was done using Wilcoxon's rank sum test for matched pairs.

\section{Congenital Red-Green Blindness (Table IV)}

The error score range using the red-green plates was 16 to 20 (mean 18.64) in the red-green colour blind group compared with 0 to 2 (mean 0.64 ) in controls. This difference in error scores was statistically significant $(p<0.01)$. 
Table IV. Results for congenital red-green blindness patients and age-matched controls

\begin{tabular}{|c|c|c|c|c|c|c|c|c|}
\hline \multicolumn{6}{|c|}{ Congenital red-green blindness } & \multicolumn{3}{|c|}{ Age-matched controls } \\
\hline \multirow{2}{*}{$\begin{array}{l}\text { Patient } \\
\text { no. }\end{array}$} & \multirow{2}{*}{$\begin{array}{c}\text { Age } \\
\text { (years) }\end{array}$} & \multirow{2}{*}{$\begin{array}{l}\text { Visual } \\
\text { acuity }\end{array}$} & \multirow{2}{*}{$\begin{array}{l}\text { No. of } \\
\text { Ishihara } \\
\text { plates } \\
\text { failed } \\
\text { (of 20) }\end{array}$} & \multicolumn{2}{|c|}{ New test error score } & \multirow{2}{*}{$\begin{array}{l}\text { No. of } \\
\text { Ishihara } \\
\text { plates } \\
\text { failed } \\
\text { (of 20) }\end{array}$} & \multicolumn{2}{|c|}{ New test error score } \\
\hline & & & & Red-green & Blue-yellow & & Red-green & Blue-yellow \\
\hline 1 & 56 & $6 / 6$ & 18 & 20 & 0 & 0 & 2 & 2 \\
\hline 2 & 20 & $6 / 6$ & 20 & 16 & 0 & 1 & 0 & 0 \\
\hline 3 & 28 & $6 / 6$ & 20 & 20 & 0 & 1 & 0 & 0 \\
\hline 4 & 25 & $6 / 6$ & 20 & 16 & 0 & 0 & 0 & 0 \\
\hline 5 & 44 & $6 / 5$ & 20 & 20 & 0 & 3 & 2 & 1 \\
\hline 6 & 33 & $6 / 6$ & 20 & 20 & 0 & 0 & 0 & 0 \\
\hline 7 & 35 & $6 / 5$ & 20 & 20 & 1 & 1 & 0 & 0 \\
\hline 8 & 40 & $6 / 9$ & 19 & 20 & 8 & 0 & 1 & 1 \\
\hline 9 & 31 & $6 / 6$ & 19 & 16 & 5 & 0 & 0 & 0 \\
\hline 10 & 56 & $6 / 9$ & 20 & 20 & 1 & 1 & 2 & 1 \\
\hline 11 & 20 & $6 / 9$ & 20 & 17 & 0 & 0 & 0 & 0 \\
\hline 12 & 50 & $6 / 9$ & 20 & 16 & 0 & 0 & 0 & 0 \\
\hline 13 & 27 & $6 / 6$ & 20 & 20 & 0 & 0 & 0 & 0 \\
\hline 14 & 56 & $6 / 6$ & 20 & 20 & 2 & 0 & 2 & 0 \\
\hline Mean & 37.21 & & 19.71 & 18.64 & 1.21 & 0.5 & 0.64 & 0.36 \\
\hline
\end{tabular}

Using the blue-yellow plates, the error score range in the red-green colour blind group was 0 to 8 mean (mean 1.21) compared with 0 to 2 (mean 0.36) in controls. There was no significant difference in the error scores between the two groups for these plates $(p>0.05)$. The results are set out in Table IV. These results confirm the ability of the new test to differentiate between the two colour axes.

\section{Optic Neuritis (Tables V, VI)}

At presentation, the optic neuritis patients had an error score range of 9 to 20 (mean 18.4) using the red-green plates and 9 to 20 (mean 17.6) using the blue-yellow plates. The ranges for the age-matched controls were 0 to 3 (mean 0.8) and 0 to 2 (mean 0.5) respectively. The optic neuritis error scores for both the red-green and blue-yellow plates of the new test were significantly higher than those of the agematched controls $(p<0.01)$.

Fluctuations in error scores for each patient were recorded throughout the 6 month follow-up period. A general trend of decreasing error score was seen, but the scores remained significantly higher than those of controls throughout the study.

At initial presentation, only 1 patient $(9 \%)$ had a visual acuity of $6 / 9$ or better. By 6 months the figure had increased to 9 eyes (82\%). At 6 months the error score range for the optic neuritis patients was 0 to 20 (mean 11.8) and 0 to 20 (mean 10.6), using the redgreen and blue-yellow plates respectively. Despite the improvement in visual acuity, there was still a significant difference in error scores, i.e. a significant loss of red-green and blue-yellow colour perception in patients compared with controls $(p<0.01)$. The results are set out in Tables $\mathrm{V}$ and VI.

\section{DISCUSSION}

Defects in colour vision are a feature of many neurological and ophthalmic conditions which cause optic nerve and/or chorioretinal dysfunctions.

Table V. Results for optic neuritis patients

\begin{tabular}{|c|c|c|c|c|c|c|c|c|c|c|c|c|c|}
\hline \multirow{3}{*}{$\begin{array}{l}\text { Patient } \\
\text { no. }\end{array}$} & \multirow{3}{*}{$\begin{array}{c}\text { Age } \\
\text { (years) }\end{array}$} & \multicolumn{3}{|c|}{ Initial } & \multicolumn{3}{|c|}{1 month } & \multicolumn{3}{|c|}{3 months } & \multicolumn{3}{|c|}{6 months } \\
\hline & & \multirow[b]{2}{*}{ VA } & \multicolumn{2}{|c|}{ Error score } & \multirow[b]{2}{*}{ VA } & \multicolumn{2}{|c|}{ Error score } & \multirow[b]{2}{*}{ VA } & \multicolumn{2}{|c|}{ Error score } & \multirow[b]{2}{*}{ VA } & \multicolumn{2}{|c|}{ Error score } \\
\hline & & & $\mathrm{RG}$ & BY & & RG & BY & & RG & BY & & $\mathrm{RG}$ & BY \\
\hline 1 & 44 & $6 / 12$ & 20 & 16 & $6 / 6$ & 12 & 12 & $6 / 6$ & 12 & 12 & $6 / 6$ & 9 & 12 \\
\hline 2 & 36 & HM & 20 & 20 & $\mathrm{CF}$ & 20 & 20 & $6 / 12$ & 20 & 20 & $6 / 12$ & 20 & 20 \\
\hline 3 & 24 & $6 / 12$ & 9 & 9 & $6 / 9$ & 6 & 9 & $6 / 9$ & 9 & 9 & $6 / 12$ & 9 & 2 \\
\hline 4 & 24 & $\mathrm{CF}$ & 20 & 20 & $6 / 18$ & 20 & 20 & $6 / 6$ & 2 & 2 & $6 / 6$ & 2 & 2 \\
\hline 5 & 24 & $6 / 60$ & 20 & 20 & $6 / 12$ & 20 & 16 & $6 / 6$ & 20 & 9 & $6 / 6$ & 20 & 9 \\
\hline 6 & 29 & $6 / 12$ & 20 & 20 & $6 / 6$ & 16 & 16 & $6 / 6$ & 20 & 20 & $6 / 6$ & 16 & 16 \\
\hline 7 & 42 & $6 / 18$ & 13 & 9 & $6 / 6$ & 9 & 9 & $6 / 6$ & 6 & 0 & $6 / 6$ & 2 & 0 \\
\hline 8 & 32 & $\mathrm{CF}$ & 20 & 20 & $6 / 36$ & 20 & 20 & $6 / 9$ & 20 & 16 & $6 / 9$ & 16 & 16 \\
\hline 9 & 42 & $\mathrm{HM}$ & 20 & 20 & $6 / 9$ & 20 & 20 & $6 / 9$ & 20 & 20 & $6 / 9$ & 16 & 20 \\
\hline 10 & 42 & $6 / 9$ & 20 & 20 & $6 / 6$ & 20 & 20 & $6 / 9$ & 20 & 20 & $6 / 9$ & 20 & 20 \\
\hline 11 & 30 & $\mathrm{CF}$ & 20 & 20 & $6 / 5$ & 12 & 12 & $6 / 5$ & 0 & 0 & $6 / 5$ & 0 & 0 \\
\hline Mean & 33.5 & & 18.4 & 17.6 & & 15.9 & 15.8 & & 13.5 & 11.6 & & 11.8 & 10.6 \\
\hline
\end{tabular}

VA, visual acuity; CF, counting fingers; HM, hand movement; RG, red-green plates; BY, blue-yellow plates. 
Table VI. Results for controls of optic neuritis patients

\begin{tabular}{lcccc}
\hline \multirow{2}{*}{$\begin{array}{l}\text { Patient } \\
\text { no. }\end{array}$} & $\begin{array}{c}\text { Age } \\
\text { (years) }\end{array}$ & VA & Red-green & Blue-yellow \\
\cline { 4 - 5 } & 46 & $6 / 9$ & 2 & 0 \\
2 & 34 & $6 / 6$ & 1 & 1 \\
3 & 24 & $6 / 6$ & 0 & 0 \\
4 & 24 & $6 / 6$ & 0 & 0 \\
5 & 24 & $6 / 6$ & 0 & 0 \\
6 & 30 & $6 / 6$ & 0 & 1 \\
7 & 43 & $6 / 6$ & 1 & 0 \\
8 & 32 & $6 / 6$ & 0 & 2 \\
9 & 44 & $6 / 6$ & 2 & 0 \\
10 & 42 & $6 / 6$ & 3 & 2 \\
11 & 32 & $6 / 6$ & 0 & 0 \\
Mean & 34.1 & & 0.8 & 0.5 \\
\hline
\end{tabular}

Generally, congenital defects tend to be stable whilst acquired defects (e.g. optic neuritis, dysthyroid eye disease, proliferative retinopathy) tend to fluctuate according to disease status.

Congenital red-green colour vision defects affect $8 \%$ of men to varying degrees. Many 'mass screening tests' have been designed to identify this defect and traditionally used to exclude these men from types of employment which require 'normal' colour vision; for example, the Ishihara test was designed and used to select railway workers. Because it is easy, quick to perform, and does not require special skills on the part of the examiner or the subject, the Ishihara test has been widely used for this purpose.

Using the new test, patients with congenital redgreen blindness as diagnosed by the Ishihara test had significantly higher error scores using the red-green plates than controls $(p<0.01)$. As expected, the error scores for the blue-yellow plates were not significantly different from those of controls $(p>0.05)$. This suggests that the new test is able to differentiate between patients with congenital red-green blindness and normal subjects using the red-green axis, and confirms that the blue-yellow axis is unaffected in congenital red-green blindness.

Over the years, the Ishihara test has also been used extensively in the clinic to test acquired colour vision defects, a function for which it was not designed. Unlike congenital defects, acquired colour vision defects can affect both the red-green and blue-yellow axes and the degree of defect can fluctuate with the disease status.

Optic neuritis is an inflammation of the optic nerve which can be idiopathic or due to a demyelinating lesion. The acute attack typically presents with pain on eye movement, sudden reduction in visual acuity in one eye and an ipsilateral relative afferent pupillary defect. Improvement in visual acuity is variable but a return to pre-attack levels usually occurs within 3 months. Despite almost complete recovery of visual acuity as measured by the Snellen acuity chart, many patients still complain of visual symptoms. These can be attributed to defects in colour vision and/or loss of contrast sensitivity. ${ }^{1,25-27}$ Evidence suggests that both red-green and blueyellow colour vision ${ }^{28}$ defects exist.

Results from this study confirm that despite recovery in visual acuity, defects in colour vision persist in optic neuritis patients. At 6 months, the error scores for both the red-green and blue-yellow plates were still significantly higher than those of controls $(p<0.01)$. Although there was considerable recovery of colour vision during follow-up, the difference remained statistically significant throughout the 6 month period. These findings are consistent with those of Menage et al. ${ }^{24}$

Further studies are in progress to look at the applications of the new test in two other acquired diseases known to cause colour vision deficit, namely dysthyroid eye disease and diabetic retinopathy. In the latter condition, blue-yellow colour deficit is reported to be an early sign of proliferative retinopathy ${ }^{29}$ for which referral to an ophthalmologist may be required.

This study shows that the new colour vision test can be used to test congenital and acquired colour vision defects as it measures both red-green and blue-yellow deficits. It is able to demonstrate visual dysfunction beyond visual acuity measurement and can be used to monitor the progress of colour vision defects caused by acquired diseases such as optic neuritis. The test offers clinicians a simple and effective tool for screening congenital colour blindness and for the diagnosis and management of acquired colour vision defects.

The authors would like to thank Dr Arnold Wilkins for his advice and help in verifying the colours used in the test. We would also like to thank Miss A. Gilvarry, Mr S. Das and $\mathrm{Mr} \mathrm{P}$. Fison for their encouragement and their help in using the test in their clinics.

Key words: Blue-yellow, Colour vision test, Pseudoisochromatic plates, Red-green.

\section{REFERENCES}

1. Griffin JF, Wray SH. Acquired colour vision defects in retrobulbar neuritis. Am J Ophthalmol 1978;86:193201.

2. Francois J, Verriest G. On acquired deficiency of colour vision, with special references to its detection and classification by means of the test of Farnsworth. Vision Res 1961;1:201-19.

3. Linksz A. The clinical characteristics of acquired color vision defects. In: Staatsma BR, Hall MO, Allen RA, editors. The retina: morphology, function and clinical characteristics, Berkeley: University of California Press, 1969:583-92.

4. Wildberger MGM, Van Lith GHM. Color vision and visually evoked response in the recovery period of optic neuritis: color vision deficiency. Third International Symposium, Amsterdam. Mod Probl Ophthalmol 1976;17:320.

5. Pinckers A. Colour vision as a diagnostic aid. Doc Ophthalmol 1982;52:393-6. 
6. Lakowski R. Theory and practice of colour vision testing: a review. Br J Ind Med 1969;26:173-89.

7. Ishihara S. Ishihara's test for colour blindness, 38 plates edn. Tokyo: Kanehara, 1987.

8. Linksz A. Reflections, old and new, concerning acquired defects of color vision. Surv Ophthalmol 1973;17:229-40.

9. Gorrell GJ. A study of defective colour vision with the Ishihara test plates. Ann Hum Genet 1967;31:39-43.

10. Thurline HC. Color blindness in children. Clin Pediatr 1972;11:295-9.

11. Mullen KT, Plant GT. Colour and luminance vision in human optic neuritis. Brain 1986;109:1-13.

12. Fallowfield L, Krauskopf J. Selective loss of chromatic sensitivity in demyelinating disease. Invest Ophthalmol Vis Sci 1984;25:1-13.

13. Ohta Y. Studies on acquired anomalous color vision. I. On the color vision of the degeneration pigmentosa retinae. Acta Soc Ophthalmol Jpn 1961;61:905-69.

14. Hong S. Types of acquired color vision defects. Arch Ophthalmol 1957;58:505-9.

15. Cox J. Colour vision defects acquired in diseases of the eye. Br J Physiol Opt 1960;17:195-216.

16. Aspinall PA, Kinnear PR, Duncan LJP, Clarke BF. Prediction of diabetic retinopathy from clinical variables and color vision data. Diabetes Care 1983;6:1448.

17. Adams AJ, Spivey BE. Color vision. In: Tasman W, editor. Duane's foundations of clinical ophthalmology, vol 2. Philadelphia: JB Lippincott, 1991:19,1-25.

18. Levinthal CF. Introduction to physiological psychology, 2nd ed. Englewood Cliffs, NJ: Prentice-Hall, 1983.

19. Farnsworth DJ. The Farnsworth-Munsell 100-hue and dichotomous tests for colour vision. J Opt Soc Am 1943;33:568-78.
20. Farnsworth D. The Farnsworth-Munsell 100-hue test for the examination of color discrimination. Baltimore: Munsell Color Co. Inc., 1957:27.

21. Bassi CJ, Galanis JC, Hoffman J. Comparison of the Farnsworth-Munsell 100-Hue, the Farnsworth D-15, and the L'Anthony D-15 Desaturated Color Tests. Arch Ophthalmol 1993;111:639-41.

22. Bowman KJ. The clinical assessment of colour discrimination in senile macular degeneration. Acta Ophthalmol (Copenh) 1980;58:337-46.

23. Hunt RWG. Measuring colour, 2nd ed. London. Ellis Horwood, 1991.

24. Menage MJ, Papakostopoulos D, Dean Hart JC, Gogolitsyn Y. The Farnsworth-Munsell 100-hue test in the first episode of demyelinating optic neuritis. Br J Ophthalmol 1993;77:68-74.

25. Bradley WG, Whitty CWM. Acute optic neuritis: its clinical features and their relationship to prognosis for recovery of vision. J Neurol Neurosurg Psychiatry 1967;30:531-8.

26. Burde RM, Gallin PF. Visual parameters associated with recovered retrobulbar optic neuritis. Am J Ophthalmol 1975;79:1034-7.

27. Saunders EACM, Volkers ACW, van de Poel JC, Van Lith GHM. Estimation of visual function after optic neuritis: a comparison of clinical tests. Br J Ophthalmol 1986;70:918-25.

28. Krill AE, Fishman GA. Acquired color vision defects Trans Am Acad Ophthalmol Otolaryngol 1971;75:1095-111.

29. Aspinall PA, Kinnear PR, Duncan LJP, Clarke BF Prediction of diabetic retinopathy from clinical vari. ables and color vision data. Diabetes Care 1983;6 144-8. 